\title{
On Competition-driven Teaching of Multidisciplinary Engineering Education: Implementation cases at University of Stavanger
}

\author{
H.G. Lemu, \\ Faculty of Science and Technology, University of Stavanger \\ N-4036 Stavanger (E-mail: Hirpa.g.lemu@uis.no)
}

\begin{abstract}
This article will reflect the experience gained on problem-based learning (PBL) projects implemented in the last six years at University of Stavanger (UiS). The PBL projects were implemented by establishing two "student-driven" student organizations, ION Racing and UiS Subsea, that design and construct Formula 1 style single seat racecar and underwater robot respectively. The student organizations simulate an engineering company that receives order from a client and delivers the product according to the customer specifications. The main objective of the projects is to stimulate the learning process in the engineering profession in a multidisciplinary environment, gain knowledge within science and engineering, and develop skills in use of advanced tools and techniques. The article highlights the student competition environment briefly and presents the result of a survey conducted on students currently participating in the PBL project. The survey result clearly indicates that the students' preference for learning is on project work in a team and hands-on exercises including laboratory works.
\end{abstract}

Keywords: Problem-based learning, project-based learning, competition-driven learning, Formula student, Remotely operated vehicle.

\section{INTRODUCTION}

As diverse teaching-learning methods have been in use at many higher education institutions, it may be difficult to find a standard method that fits for all. In general, the classical teaching/learning methods are classified as deductive and inductive. While the former derives theories and applications based on the basics such as particular observations or measurement data, the latter is considered to be a discovery style [1]. Problem-based learning (PBL) is an inductive learning method and considered to be the "best" method for engineering students [13]. PBL can be defined as problem-based or project-based approach. Though there exists slight difference in the two concepts, in terms of the role of student and teacher, the two concepts are synonymously used in this article.

Understanding the demands from the progressively advancing industrial technology and the needs for the skills and competences to cope with the progresses, some but limited studies are reported on the impact of PBL on engineering education. Yadav, et al. [4] reported on an investigation conducted on the impact of PBL approach in conceptual understanding and perceptions of learning of electrical engineering students using PBL as compared to lectures. In this study, the researchers found that the learning gains of the students in the PBL team were twice their gains from traditional lecture. However, they observed that the students' perception was the reverse, i.e. they thought they learned more from traditional lecture.

The teaching-learning style in engineering profession requires to actively follow the developments in the modern engineering profession that is characterized by dynamicity and uncertainty, sometimes even dealing with issues with competing interests. Engineers that handle such issues need not only the technical competence, but also other social skills such as teamwork and legal consequences of, for example, design decisions. However, the predominant 
learning-teaching method still involve the traditional "chalk and talk" approach [5]. In order to face the challenge and address the modern needs, it demands to see beyond the accepted teaching philosophy of engineering education.

The engineering profession in general and the mechanical engineering discipline in particular deals with the planning and creation of physical objects such as machines and other mechanical systems. This creation process, which is conducted through engineering design, requires not only the academic knowledge such as the fundamental mechanics and mathematics, but also the innovative elements that include creativity, imagination and intuition. The engineering educations at universities in general focus on the academic elements and engineers graduate with minor hands-on practice. PBL approach is considered as a key tool to stimulate the innovative elements of engineering education and equip the graduates with better skills to let them fit in the job market.

For any person who is concerned to know about the impact of specific teaching for the students and the society at large, there may exist a number of questions that remain without clear and concise answer. Among those, the following two questions are considered to be the forefront:

1) What is the best teaching method that can make the learning outcome as effective as possible?

2) What is the content, depth and breadth of the teaching material of a specific course that significantly contribute to the dynamism in the society?

In this article, the author would like to reflect on experiences gained on a PBL approach implemented in the last six years at University of Stavanger (UiS). The article presents both the experience gained through the years of the implementation of PBL approach and the student feedbacks on a survey conducted to investigate the extent to which the goals of the project are achieved. The focus of the article is not necessarily to explain about the application of PBL method in engineering education, which is quite common in today's university teachinglearning environment and reported in several scientific publications [2, 5 - 8], but to highlight the benefits when the method is implemented in a competition-driven, student-centered and multidisciplinary environment.

The article is organized as follows. Section 2 provides some backgrounds of the implementation of a PBL project and highlights the important objectives for initiating the project for engineering students at UiS. Then, some of the measureable results are presented in Section 3. In order to assess student feedback on the implementation challenges and achieved results, a survey was conducted where students actively participating in the ION Racing team responded to a questionnaire. Section 4 of the article discusses the result of the survey. Finally, the conclusions drawn from the analysis are briefly presented in Section 5.

\section{BACKGROUNDS AND OBJECTIVES OF THE PBL PROJECT AT UIS}

The implementation of the PBL projects described in the article is supplement to the existing teaching and learning strategies or culture in engineering. This and similar projects involve studentcentered approach and establish open learning platform for the students. To implement the PBL approach, two student-driven projects or student organizations, namely, ION Racing and UiS Subsea, were established in 2011 and 2013 respectively. The student organizations are studentdriven because they manage all activities of the organization and simulate an engineering organization that delivers products according to the design specification of the client. For instance, ION Racing is a student team that recruits students from diverse disciplines and academic levels to design and build a single-seat racecar whose design specifications are defined by Institute of Mechanical Engineers (IMechE) [9]. In this case, IMechE acts as a client and the racecar is the product delivered when the students participate in the international student competition called Formula Student. The competition is organized annually at Silverstone, London. Nowadays, there are many similar engineering student competitions around the world, 
while the competition at Silverstone, where the prestigious Formula 1 competition takes place, is the most famous and attracts students from more than 40 countries each year.

In a similar manner, UiS Subsea recruits those students interested in marine and subsea related technology. The UiS Subsea organization simulates an engineering company that produces underwater robots or commonly called remotely operated vehicles (ROV) in accordance with the mission specifications of Marine Advanced Technology Education (MATE) center in USA. MATE arranges the competitions to stimulate the learning process of marine technology education that covers the application of science and engineering knowledge and other advanced tools and techniques to the understanding and use of the marine environment [10]. Every year, MATE selects different competition missions and locations so that the designed and constructed ROV can perform the specified tasks. In the last four competitions in which UiS Subsea participated, the specified missions were the following.

- 2017 (Port of Long Beach, LA), Port Cities of the Future: Commerce, Entertainment, Health, and Safety

- 2016 (NASA's Neutral Buoyancy Lab in Houston, Texas, USA), From the Gulf of Mexico to Jupiter's Moon Europa: ROV encounters in inner and outer space.

- 2015 (St. John's, Canada), ROVs in Extreme Environments: Science and industry in the Arctic.

- 2014 (Michigan, USA), Exploring the Great Lakes: Shipwrecks, Sinkholes, and Conservation in the Thunder Bay National Marine Sanctuary

In line with the competition philosophy of IMechE and MATE, both project teams at UiS establish a platform that lets students learn science, technology, engineering and mathematics (commonly referred to as STEM) at their own initiative, because they are student-centered, and get prepared for an engineering career.

\subsection{Common Features of the Teams}

While implementing the project, both student organizations have many features in common including the following

- Multidisciplinary: involve students from Mechanical Engineering, Electronics or Electrical Engineering, Computer Science, Engineering Management, etc.

- Integrated into the curriculum: students conduct semester projects, bachelor projects and master theses on parts of the racecar and the ROV.

- Learning by practice - students in the teams get access to the workshops and mechanical/material labs to get hands-on skills.

\subsection{Defined Parameters for Sustainability and Goals}

Before starting the PBL projects at UiS, the important parameters that were considered issues of concern for the sustainability of the projects and the potential benefits to the teaching learning process were assessed. The critical parameters were identified to be 1) student motivation and 2) availability of funding. As student participation is purely voluntary and their activity is an extra-curricular activity, maintaining the motivation using some factors was found crucial. Some may participate merely out of personal interest, while others may need other motivation factors. As a result, some of the student activities in the teams are integrated into the curriculum activities such as semester projects, bachelor theses and master theses, so that the students can produce credits.

Conducting the project with about 50 students per year in each team is an expensive business. Therefore, funding issue is considered as one of the decisive parameters for sustainability of the project. The funding is mainly provided by companies in the region in the form of sponsorship and other forms of support both in kind and services. For instance, only in 2015, about 40 companies were registered in the list sponsors for ION Racing team. The university 
(UiS) has also been generous to support the activities of the students in both cash, work areas and materials.

Among many others, the following are the stated goals for the projects:

- Get hands-on skills, use achieved knowledge and further develop to solve engineering problems,

- Learn a good design process - from product idea generation to final product realization,

- Understand how mechanical components function in a mechanical system,

- Learn the influence of design choices on performance of a mechanical system,

- Stimulate innovation and creative thinking,

- Stimulate student recruitment to engineering education at UiS,

- Stimulate and strengthen industry - university cooperation through sponsorship agreements,

- Stimulate competition driven learning,

- Develop experience in teamwork and project execution.

\subsection{Competition criteria}

The main goals of the student competition organizing institutions, IMechE and MATE, are to challenge the creativity, engineering imagination and knowledge of the students. In other words, the focus is not on the object (racecar or ROV) they produce, but the process they go through, the challenge they face and the knowledge, skill and competence they gain that is the most important. In the case of the racecar, for instance, different parameters are used to judge each car with other competitors.

As shown in Fig. 1 [9], the racecar is judged in terms of two general events: static event and dynamic event. The three competition parameters in the static event are engineering design, business presentation, and cost and sustainability issues. Creativity, imagination and efforts of the students is judged in the engineering design evaluation session. This session includes convincing the judges on the decisions taken on selection of materials, component form and size and production method. Upon presenting their product in the business presentation session, the students demonstrate their ability to market their products.
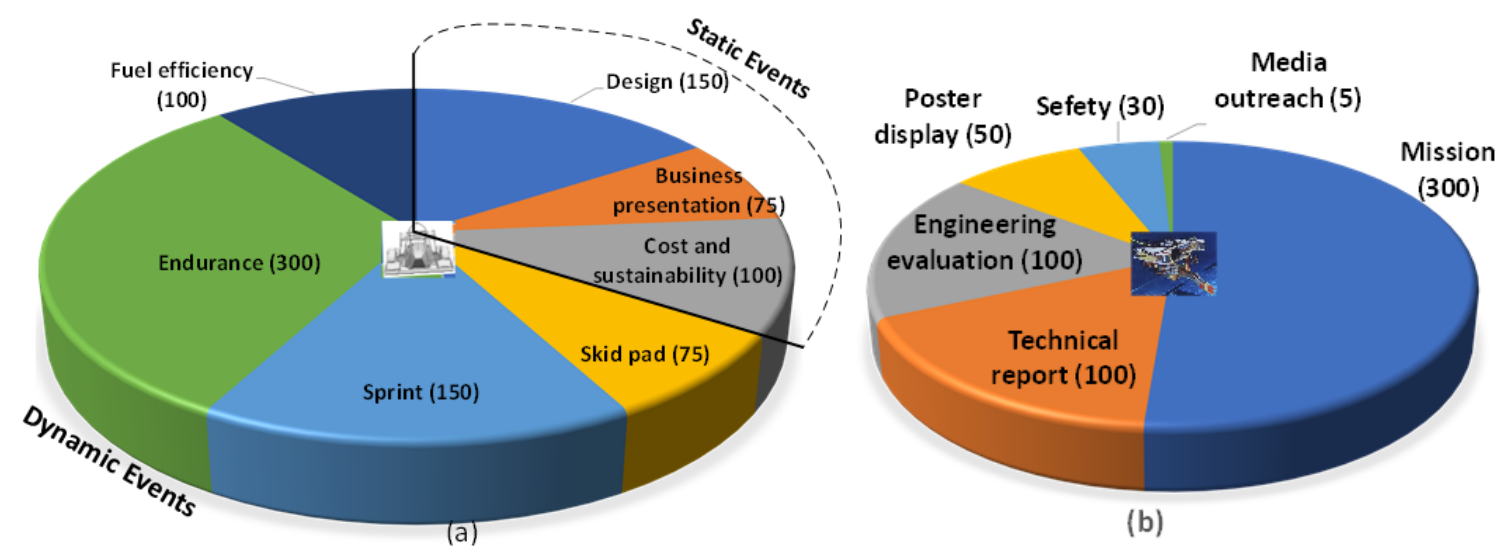

(b)

Fig. 1. Competition parameters and achievable max. scores (a) Formula student (b) MATE competition

The major mission for the racecar is completing the endurance event, which challenges the car to finish a $22 \mathrm{~km}$ long drive track with one time driver shift. One goal of this event is to test the reliability of the students' design work since no repair is allowed during the event. The second goal is to check the fuel efficiency of the car because no refueling or recharging is permitted until the end of the event. The competition parameters of the racecar, in general, do not vary from year to year, but IMechE changes some of the competition regulations from time to time. The MATE competition, on the other hand, challenges students with new missions every year [10]. 


\section{PROJECT RESULTS}

Until this year (academic year 2016/17), UiS students have participated in six competitions of the racecar and four competitions of the ROV. The students design and build the vehicles mainly on voluntary basis, and in some cases students produce study points (credits) through semester projects and bachelor/master theses. The number of bachelor/master theses written related with the PBL projects together with disciplines involved are shown in Table 1. According to the MATE competition regulations, only undergraduate students are allowed to participate. This is the main reason that no MSc thesis has been written as part of the ROV project. Since the students participate each year with new product, the project keeps them busy throughout the whole academic year (September - June). In addition to the physical production of the racecar and/or the ROV, some efforts are done to let students present their work on international conferences $[11,12]$. The most important result, which is our main goal, is however, the knowledge and skill the students gain in a multidisciplinary learning environment.

Table 1. List of BSc \& MSc theses written based on ION the race car and the ROV projects (2012 -17)

\begin{tabular}{|l|c|c|c|c|c|c|}
\hline Discipline & \multicolumn{2}{|c|}{ Bachelor thesis } & \multicolumn{2}{c|}{ Master thesis } & \multicolumn{2}{c|}{ Total } \\
\hline & Racecar & ROV & Racecar & ROV & Racecar & ROV \\
\hline Mechanical Engineering & 69 & 24 & 3 & - & 72 & 24 \\
\hline Electrical Engineering & 23 & 25 & 1 & - & 24 & 25 \\
\hline Computer Science & 8 & 5 & - & - & 8 & 5 \\
\hline Subtotal & 100 & 54 & 4 & - & 104 & 54 \\
\hline Total & \multicolumn{2}{|c|}{154} & 8 & \multicolumn{2}{c|}{158} \\
\hline
\end{tabular}

\section{ARE THE STATED GOALS ACHIEVED? - REFLECTIONS FROM STUDENTS}

To assess whether some of the objectives are achieved or not, questionnaires were prepared and distributed to students that are active members of ION Racing team in the 2016/2017 academic year. The questionnaire consisted of 15 questions. In general, the questions are intended to collect information about:

- backgrounds and composition of the team,

- motivation for the student to participate in the team's activities,

- role/impact of project-based learning for the student's performance,

- student preference of teaching methods and how PBL approach is conceived by the students.

In total 32 students responded to the questionnaire, and the composition of the students is shown in Table 2. As the table shows, the team (the project) involves students from diverse disciplines and hence is multidisciplinary. Students from all levels of the study programs, including master students are also participating. From the total team members that responded to the survey, onethird are female. In the following sections, some of the stated goals are analysed based on the students' feedbacks.

Table 2. Composition of team members in the survey

\begin{tabular}{|c|c|c|c|c|c|c|c|}
\hline Field of study & \multicolumn{2}{|c|}{ Gender } & \multicolumn{4}{|c|}{ Academic level (year) } & \multirow[t]{2}{*}{ Total } \\
\hline & Male & Female & $1^{\text {st }}$ year & $2^{\text {nd }}$ year & $3^{\text {rd }}$ year & $\mathrm{MSc}$ & \\
\hline $\begin{array}{l}\text { Mechanical } \\
\text { Engineering }\end{array}$ & 10 & 6 & 2 & 3 & 10 & 1 & 16 \\
\hline Electrical Engineering & 9 & & 2 & 1 & 5 & 1 & 9 \\
\hline Computer Science & 3 & 2 & 0 & 3 & 2 & & 5 \\
\hline Others & $2 *$ & & 2 & & & & 2 \\
\hline Total & 24 & 8 & 6 & 7 & 17 & 2 & 32 \\
\hline
\end{tabular}

* Petroleum Engineering (1) and Preparatory year (1) 


\subsection{Student recruitment}

Figure 2 depicts the student response on two questions that were put forward to assess if some of the stated goals are achieved and to understand if running this and similar projects have any benefit in terms of the teaching-learning process including student recruitment. As shown Fig. 2(a), the number of team members who had pre-information about the formula Student project at UiS is larger than those who did not. In other words, this may imply that most of the team members decided to join the team before they joined the university. This is also confirmed by the response in Fig. 2(b), which indicates that the project has influenced their choice of UiS.

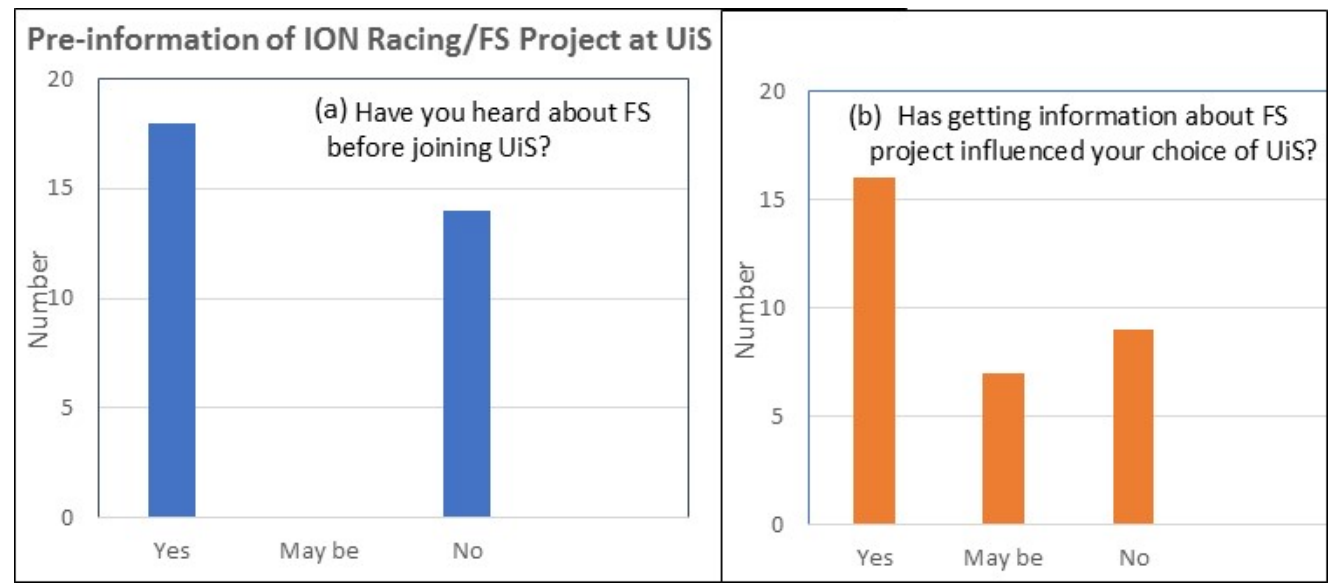

Fig. 2. Influence of pre-information about PBL projects on student choice

\subsection{Motivation and impact for students}

The conducted survey (Fig. 3) indicates that the main motivation for the students to voluntarily participate in the PBL projects is to get hands-on skills. Further, getting better prepared for future career opportunities in modern engineering field and being in a social environment are additional reasons. The assessment also shows that the project has given them more motivation for learning in other courses.

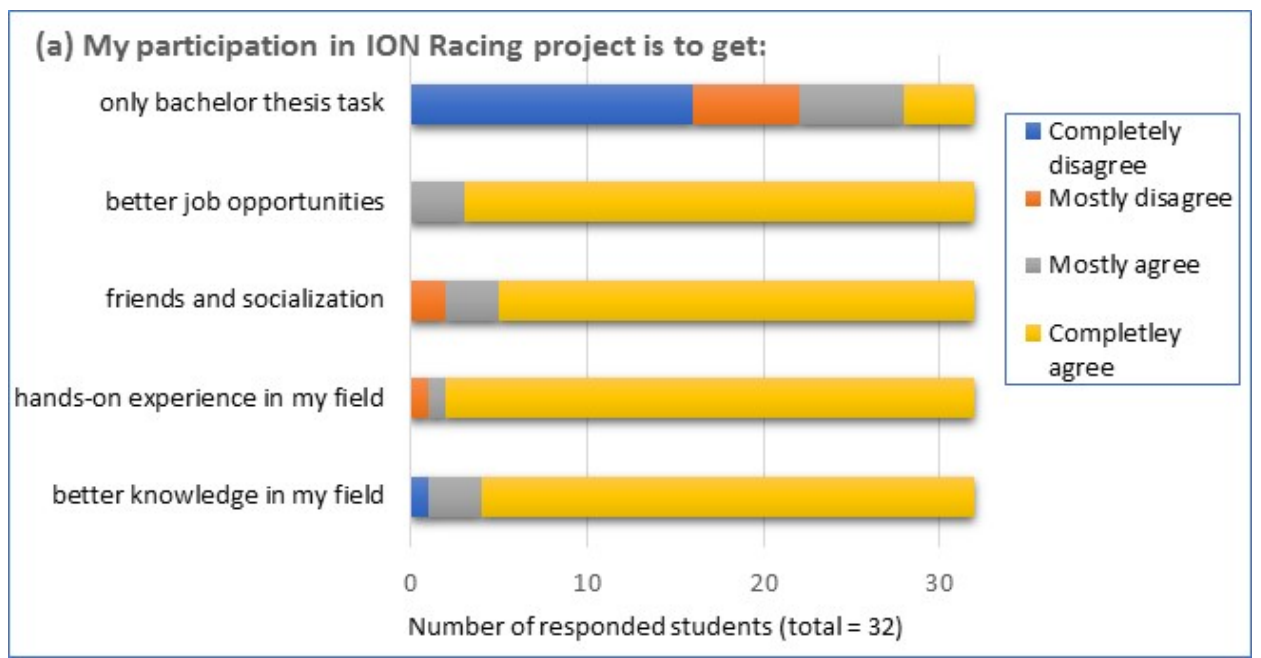




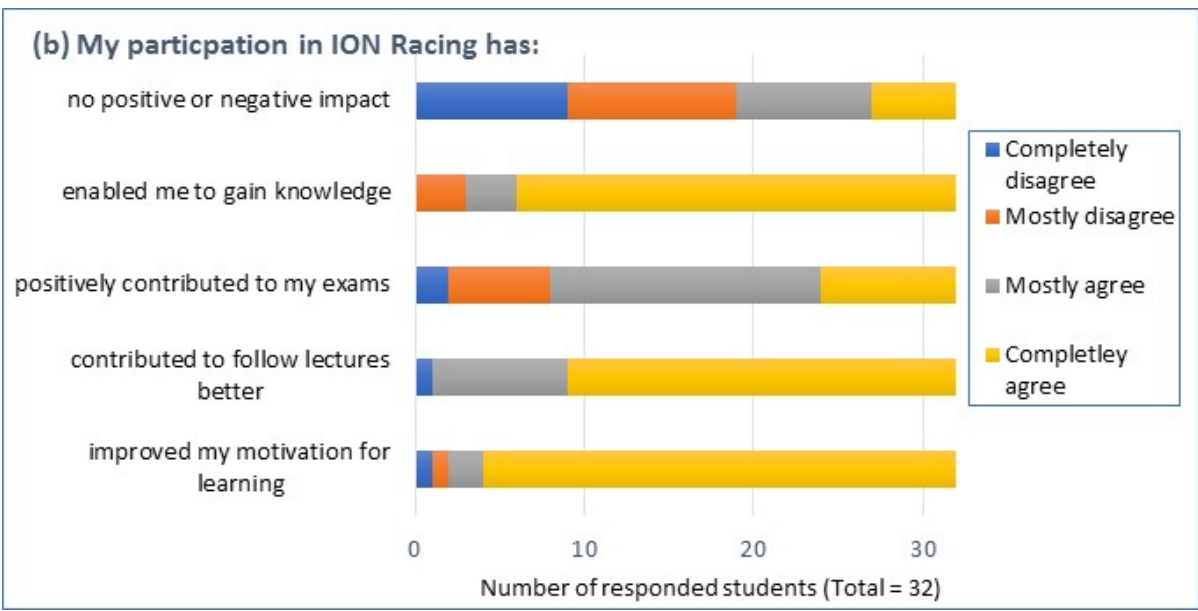

Fig. 3. (a) Motivation and (b) impacts for student participation in ION Racing

\subsection{Impacts of project-based courses on student performance}

Though, in our experience, PBL approach is demanding for both students and teachers, it is a learning approach that simulates the real-world problem and allows students to use their imagination to innovate, explore, analyse, synthesize and interpret the problem in hand. Without any doubt, it enables them to better understand their study and effectively achieve targeted learning outcomes. The question from the outset is if students see this as a benefit or perceive that the better learn in PBL approach. To get some indications on this issue, two questions were asked in the survey whose results are given by bar plots in Fig. 4 (a) and (b). As depicted, project work in a team and hands-on exercises including laboratory activities are the most favoured choices by the students followed by the classical lecturing. Individual exercises are also relatively preferred as $2^{\text {nd }}$ and $3^{\text {rd }}$ choices while group exercises are the least favoured in terms of learning effect. Figure 4(b) compares the students' performance in terms of average grades and understanding of the subject matter for a project-based course against a course without project works. The assessment clearly shows that the students have higher average grades and better understanding in a project-based course.

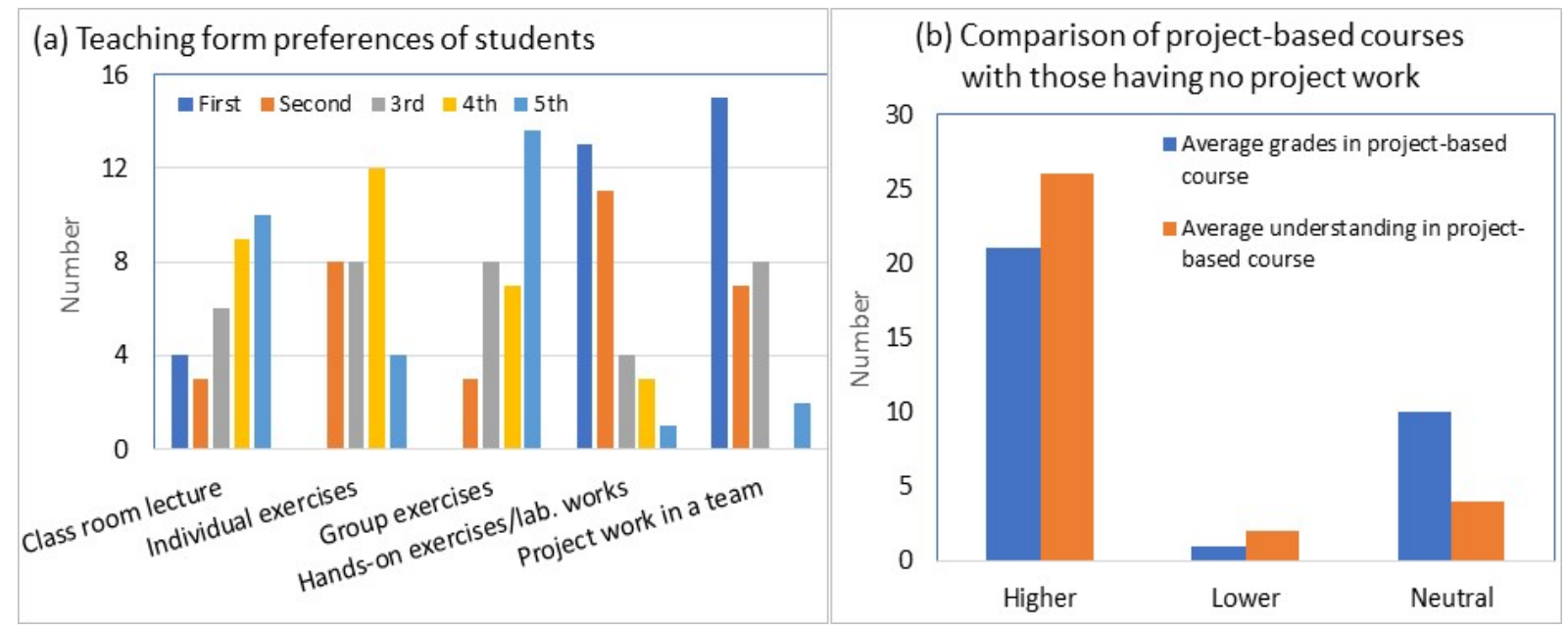

Fig. 4. Role of PBL (a) preference of teaching form and (b) comparison with no-project course

\subsection{Is the "chalk and talk" approach still dominating?}

A classical project-based learning approach can be implemented at individual course level, but it may not lead to a student-centered learning environment. In such approach, students get better opportunity to work on a problem that is close to professional reality, but they do not have the freedom to fully manage their time and resources [13], compared to student-centered projects such as those in ION Racing and UiS Subsea. 
Because the author of this article has no full overview of the teaching methods used at the faculty, and in order to have certain understanding of the extent of project-based learningteaching approach at course level, the following question was forwarded to the students:

"What is the percentage of courses you have taken at UiS that involve project work in the teaching or evaluation?"

The students' feedback, surprisingly, confirms that the existing learning-teaching method still predominantly uses the "chalk and talk" approach. Twenty-four student from 32 responded that project work is implemented in less than $30 \%$ of the courses they attend, while the rest responded that project work represents about $50 \%$. The difference in the response of the students can be due to the fact that the students are from diverse discipline.

The result of this survey is an indication that our teaching methods are still dominated by the classical approach. On the other hand, we observe that the engineering profession is in a dynamic change. Thus, it demands that the engineering graduates be equipped by the necessary knowledge skill and competence, in particular, methods of solving engineering problems that is characterized by huge uncertainty.

\section{CONCLUSION}

In summary, the two student organizations at UiS have contributed significantly to a positive learning-teaching environment and many similar PBL projects are initiated due to the positive impacts observed. The teams have created a close contact between the university and the industry and promoted the university both at national and international level. The reported student survey shows also that project-based learning is the most favored teaching method for the students learning outcome. This can be because a PBL project lets the students learn in a student-centered environment where they are challenged with a practical problem and explore to get the solution. However, this cannot be achieved without costs. Students participating in PBL projects are expected to spend much extra time and be dedicated for the teamwork. To what extent this affects their performance in other courses has been roughly investigated in this report, but further studies are required.

Though PBL is accompanied with a number of challenges, both for students and institutions, it is highly recommended for engineering students, among others, for the following reasons:

- To equip students with important practical skills and develop confidence in their knowledge either to start own business or to join the job market.

- To create an environment where students work in a multidisciplinary environment.

- To create an environment for students to freely think, innovate and realize their idea.

- To raise the quality of education for the academic institutions.

- To support the engineering industries in their need for skilled manpower.

\section{ACKNOWLEDGEMENT}

The contribution of all students in both teams is highly appreciated. The author would like particularly thank those students who participated in the student survey conducted for this study.

\section{REFERENCES}

[1]. Felder, R.M., and Silverman, L.K. (1988) Learning and teaching style in engineering education, Engineering Education, 78(7), pp. 674-681. http://www.academia.edu/download/31039406/LS-1988.pdf

[2]. Hmelo-Silver, C.E. (2004) Problem-based learning: What and how do students learn? Educational Psychology Review, 16(3), pp. 235 - 266. 
[3]. Bell, S. (2010) Project-based learning for the $21^{\text {st }}$ century: skills for the future, The clearing house: Journal of Educational Strategies, Issues and Ideas, 83(2), pp. 39 - 43. Doi: 10.1080/00098650903505415.

[4]. Yadav, A., Subedi, D., Lundeberg, M. A., and Bunting, C. F. (2011) Problem-based Learning: Influence on Students' Learning in an Electrical Engineering Course. Journal of Engineering Education, 100(2), pp. 253-280. doi: 10.1002/j.2168-9830.2011.tb00013.x

[5]. Mills, J. E., and Treagust, D. F. (2003) Engineering education - is problem-based or project-based learning the answer?, Australian journal of education, 3(2), pp. 2 - 16. http://www.aaee.com.au/ journal/2003/mills_treagust03.pdf.

[6]. Allen, D.E., Donham, R.S. Bernhardt, S.A. (2011) Problem-Based Learning, New directions for teaching and learning, No. 128, Wiley Periodicals, Inc. Wiley Online Library, doi: 10.1002/tl.465.

[7]. Fink, F.K., (1999) Integration of engineering practice into curriculum - 25 years of experience with problem based learning. In 29th ASEE/IEEE Frontiers in Education Conference, Nov. 10-13, 1999, San Juan, Puerto Rico. http://fie.engrng.pitt.edu/fie99/

[8]. Kjersdam, F. (2004) Tomorrow's engineering education - The Aalborg experiment, European Journal of Engineering Education, 19(2), pp. 197-203. http://www.tandfonline.com/doi/abs/10.1080/03043799408923285

[9]. IMechE home page: http://www.imeche.org/ (Last visited: 2017.09.12).

[10]. MATE home page: http://www.marinetech.org/ (Last visited: 2017.09.12).

[11]. Olsen, E. V., and Lemu, H. G. (2015) Mechanical Testing of Composite Materials for Monocoque Design in Formula Student Car, World Academy of Science, Engineering and Technology, International Journal of Mechanical, Aerospace, Industrial, Mechatronic and Manufacturing Engineering, 10(1), pp. 1-9. http://www.waset.org/publications/10003140

[12]. Øygarden, B., Bruset, M., Lemu, H.G. (2016), Multibody Dynamics Simulation of ROV Manipulator Designed for Student Competition. In: Advanced Manufacturing and Automation VI. Atlantis Press, pp. 225 - 232.

[13]. Heitmann, G. (1996) Project-oriented study and project-organized curricula: A brief review of intentions and solutions, European Journal of Engineering Education, 21(2), pp. 121-131. http://dx.doi.org/10.1080/03043799608923395. 